\title{
Validation of a portable nitric oxide analyzer for screening in primary ciliary dyskinesias
}

\author{
Amanda Harris ${ }^{1,2}$, Esther Bhullar ${ }^{1}$, Kerry Gove ${ }^{2}$, Rhiannon Joslin ${ }^{1}$, Jennifer Pelling ${ }^{1}$, Hazel J Evans ${ }^{1,2}$, \\ Woolf T Walker ${ }^{1,2,3}$ and Jane S Lucas ${ }^{1,2,3^{*}}$
}

\begin{abstract}
Background: Nasal nitric oxide ( $\mathrm{nNO}$ ) levels are very low in primary ciliary dyskinesia (PCD) and it is used as a screening test.

Methods: We assessed the reliability and usability of a hand-held analyser in comparison to a stationary nitric oxide (NO) analyser in 50 participants (15 healthy, 13 PCD, 22 other respiratory diseases; age 6-79 years). Nasal NO was measured using a stationary $\mathrm{NO}$ analyser during a breath-holding maneuver, and using a hand-held analyser during tidal breathing, sampling at $2 \mathrm{ml} / \mathrm{sec}$ or $5 \mathrm{ml} / \mathrm{sec}$. The three methods were compared for their specificity and sensitivity as a screen for PCD, their success rate in different age groups, within subject repeatability and acceptability. Correlation between methods was assessed.

Results: Valid nNO measurements were obtained in 94\% of participants using the stationary analyser, $96 \%$ using the hand-held analyser at $5 \mathrm{ml} / \mathrm{sec}$ and $76 \%$ at $2 \mathrm{ml} / \mathrm{sec}$. The hand-held device at $5 \mathrm{ml} / \mathrm{sec}$ had excellent sensitivity and specificity as a screening test for PCD during tidal breathing (cut-off of $30 \mathrm{~nL} / \mathrm{min}, 100 \%$ sensitivity, $>95 \%$ specificity). The cut-off using the stationary analyser during breath-hold was $38 \mathrm{~nL} / \mathrm{min}$ (100\% sensitivity, $95 \%$ specificity). The stationary and hand-held analyser $(5 \mathrm{ml} / \mathrm{sec}$ ) showed reasonable within-subject repeatability(\% coefficient of variation $=15$ ).
\end{abstract}

Conclusion: The hand-held NO analyser provides a promising screening tool for PCD.

Keywords: Nasal nitric oxide, Primary ciliary dyskinesia, Nitric oxide analyser

\section{Background}

Primary ciliary dyskinesia (PCD) is an autosomal recessive condition in which abnormal ciliary function leads to impaired mucociliary clearance and consequent recurrent upper and lower respiratory tract infection [1]. Approximately half the patients have situs inversus and male infertility is common [1]. Early diagnosis is important to ensure appropriate management and counselling; several studies suggest that early diagnosis and treatment improves long-term prognosis. To comply with European consensus guidelines diagnosis of PCD includes investigations requiring access to highly specialised

\footnotetext{
* Correspondence: jlucas1@soton.ac.uk

'Primary Ciliary Dyskinesia Centre, University Hospital Southampton NHS Foundation Trust, Southampton, UK

${ }^{2} \mathrm{NIHR}$ Southampton Respiratory Biomedical Research Unit, University of Southampton and University Hospital Southampton NHS Foundation Trust, Southampton, UK

Full list of author information is available at the end of the article
}

equipment and diagnostic scientists [2-4]. Such facilities are not widely available, contributing to the inequality of diagnosed cases throughout Europe [5]. Nasal NO (nNO) is characteristically low in PCD [6,7], so much so that $\mathrm{nNO}$ is recommended as a pre-diagnostic screening test for the condition $[2,3,8-10]$. Until recently, the only commercially available analyzers for measuring $\mathrm{nNO}$ were non-portable desktop analyzers which are extremely expensive. A reasonably priced, practical method of measuring $\mathrm{nNO}$ might improve the disparity in diagnosis and reduce diagnostic costs by reliably identifying patients for referral to specialist centres. A number of hand-held devices have proved beneficial for measuring fractional exhaled nitric oxide in patients with asthma [11-14] in clinical and research settings. Commercially available hand-held analyzers have recently been adapted to measure nNO in breath-hold and tidal breathing modes $[15,16]$. A study of PCD and CF patients reported a hand-held device to be as effective as

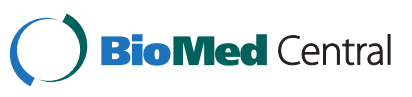


the stationary analyser for assessing $\mathrm{nNO}$ during silent and humming exhalation [17]. Furthermore, a recent Danish study has showed that tidal breathing nNO measured by a hand-held NO device discriminates between PCD, cystic fibrosis (CF) and healthy controls (HC) [18]. PCD is rare and no center has access to large numbers of patients. The two published studies using hand-held devices have respectively assessed $\mathrm{nNO}$ in only 14 PCD patients during silent and humming single breath exhalation [17] and 16 PCD patients during tidal breathing and during a velum closure maneuver [18]. Our data study therefore adds to the limited data, using a similar tidal breathing maneuver to that used in the Danish study. The aim of our single center cross-sectional study was to evaluate the ability of a commercially available analyzer $\left(\mathrm{NIOX} \mathrm{MINO}^{\circ}\right)$ to discriminate between $\mathrm{PCD}$, other respiratory diseases and healthy controls in comparison to a 'gold standard' chemiluminescence analyser (NIOX ${ }^{\oplus}$ Flex).

\section{Methods}

This study was approved by Southampton and South West Hampshire Research Ethics Committee A (06/ Q1702/109 and 08/H0502/126). All subjects gave written informed consent.

\section{Participants}

Fifty people consented to participate in this study, including 15 healthy volunteers, 13 with PCD and 22 with other respiratory disorders. Children and adults with PCD, cystic fibrosis (CF) $(n=6)$, and non-CF non-PCD chronic suppurative lung disease (CSLD) $(n=7)$ were recruited from specialist PCD and respiratory clinics. Those with asthma +/- hay fever $(n=9)$ were recruited from amongst staff/students and from respiratory clinics.

Healthy participants completed a short questionnaire to exclude disease that might affect nitric oxide levels. PCD was diagnosed at Southampton's national PCD centre by analysing respiratory epithelia ciliary beat frequency and pattern using high-speed video microscopy in patients with a suggestive history $[2,4,19]$. Diagnosis was supported by assessment of ciliary ultrastructure by transmission electron microscopy (TEM). In some cases diagnosis was further clarified by analysis of redifferentiated cilia following culture of the airway epithelial cells at an air liquid interface. CF diagnosis was based on compatible history, an abnormal sweat test and/or CF genotyping. CSLD participants were recruited from patients with a chronic history of purulent sputum referred to the PCD diagnostic service who had the diagnosis of PCD and CF excluded. They had not necessarily had a HRCT; bronchiectasis had therefore not been radiologically excluded nor confirmed. Asthma diagnosis was selfreported amongst staff and students.

\section{Measurement of airway nitric oxide}

Two different devices were used: NIOX $\mathrm{MINO}^{\circ}$ and $\mathrm{NIOX}^{\odot}$ Flex analysers. Measurement of nNO levels using NIOX $^{\oplus}$ Flex (Aerocrine, Sweden) uses chemiluminescence with sampling at $5 \mathrm{ml} / \mathrm{s}$ [20], whilst the NIOX $\mathrm{MINO}^{\circ}$ uses an electrochemical sensor and provides a result after sampling for 90 seconds at $2 \mathrm{ml} / \mathrm{s}$ or for 45 seconds at $5 \mathrm{ml} / \mathrm{s}$. The analyser only provides a result if uninterrupted sampling has been maintained throughout this sampling time. NIOX $\mathrm{MINO}^{\circ}$ can also sample during tidal breathing.

The $\mathrm{NIOX}^{\oplus}$ Flex analyser was maintained, calibrated and tested according to manufacturer's guidelines. Measurements were made by health care professionals who had been trained following a standard operating procedure derived from the manufacturer's guidelines.

In brief, ambient NO was noted before testing patients. All patients were symptomatically free of viral infection or respiratory exacerbation. Participants were requested to blow their nose before testing. A nasal probe sampled gas aspirated from the nostril at a rate of $5 \mathrm{ml} / \mathrm{sec}$ during a breath-holding maneuver. Patients held their breath for approximately 20 seconds until the real-time analyser recorded a plateau in nitric oxide concentrated from the aspirated gas. The measurement was recorded from a steady $\mathrm{nNO}$ concentration plateau of at least 4 seconds. Three measurements within $10 \%$ were obtained for each participant using the same nostril and the maximum nNO reading was recorded. $\mathrm{nNO}$ concentration in parts per billion ( $\mathrm{ppb}$ ) were converted to NO production $(\mathrm{nL} / \mathrm{min})$ using the equation $\mathrm{NO}$ production $(\mathrm{nL} / \mathrm{min})=\mathrm{nNO}$ concentration (ppb) x sampling flow rate (litres/min).

The NIOX $\mathrm{MINO}^{\circ}$ was used in nasal mode. A nasal probe sampled gas aspirated from the nostril at $5 \mathrm{mls} / \mathrm{sec}$ and was then repeated at $2 \mathrm{ml} / \mathrm{sec}$. Following ATS [20] and manufacturer's guidelines we initially attempted these measurements during breath-holding manoeuvres To obtain a test result the participant needed to achieve uninterrupted sampling for 45 seconds whilst sampling at $5 \mathrm{ml} / \mathrm{sec}$ or 90 seconds at $2 \mathrm{ml} / \mathrm{sec}$. Breath holding for this duration was not achievable even by healthy adult volunteers and it was decided to abandon this maneuver. Instead we followed the alternative method suggested by the manufacturers of sampling nasal gas at $2 \mathrm{ml} / \mathrm{sec}$ and $5 \mathrm{ml} / \mathrm{sec}$ during open mouth breathing. This non-velum closure technique has previously been confirmed as reproducible and valid using a stationary chemiluminescence analyser [21]. Three recordings at each rate were attempted, and the highest was taken.

\section{Usability and reliability of analysers}

The multidisciplinary clinical PCD team who undertook these measurements (paediatrician, PCD nurse specialist, PCD respiratory physiotherapist and respiratory 
technicians) discussed the pros and cons of the analysers. Their consensus opinions were recorded.. The success rate for obtaining a measurement with each analyser was recorded.

\section{Statistical analyses}

The highest of three measurements for each method was recorded. Nasal $\mathrm{NO}$ values were $\log _{10}$ transformed where appropriate because data was not normally distributed. Comparisons between disease groups were made using unpaired t-tests. Comparisons between analyzers were made using paired t-tests. Receiver Operating Characteristic (ROC) curves were used to determine cut of values, sensitivity and specificity. Pearson correlation coefficients were calculated to investigate correlation between $\mathrm{nNO}$ values obtained with the $\mathrm{NIOX}^{\bullet}$ Flex and NIOX MINO ${ }^{\circ .}$ Brand Altman plots were constructed with the difference of measurements from the two analyzers plotted against the mean of the two methods. The reproducibility of analyzers was reported as the intrasubject\% Coefficient of Variability (\%CV); this was calculated by calculating the standard deviation for the three measurements taken using each protocol, and dividing that by the triplicate mean, and multiplying by 100 . Data were analyzed using statistical analysis software SPSS version 19.0.0 (IBM, USA).

\section{Results}

Valid readings were obtained in 47 participants using the NIOX $^{\circ}$ Flex breath-hold protocol. Three participants (aged 5, 8 and 8 years) were unable to breath-hold for 20 seconds to obtain a technically acceptable measurement. Using the NIOX $\mathrm{MINO}^{\circ}$ healthy adults were unable to manage the breath-hold protocol of 45 seconds for $5 \mathrm{ml} / \mathrm{sec}$ or 90 seconds for $2 \mathrm{ml} / \mathrm{sec}$ and we abandoned these protocols with no resulting data. However measurement during tidal mouth breathing using the NIOX MINO $^{\circ}$ successfully provided data for 48 participants at a sampling rate of $5 \mathrm{ml} / \mathrm{sec}$ and 38 participants at $2 \mathrm{ml} / \mathrm{sec}$. The mean (range) ages of participants in each group were: healthy controls 31 years (8-65), PCD 23 years (5-71), CF 15 years (6-29), asthma 35 years $(12-59)$ and CSLD 36 years (8-79).

\section{Nasal NO as a screening tool for PCD}

Using the $\mathrm{NIOX}^{\circ}$ Flex, patients with PCD had significantly lower levels of $\mathrm{nNO}$ than healthy controls $(\mathrm{p}<0.001), \mathrm{CF}$ $(\mathrm{p}=0.003)$, asthma $(\mathrm{p}<0.001)$ and $\operatorname{CSLD}(\mathrm{p}=0.005)$. Statistically lower $\mathrm{nNO}$ values were similarly obtained in patients with $\mathrm{PCD}$ when using the NIOX $\mathrm{MINO}^{\circ}$ at $5 \mathrm{ml} / \mathrm{sec}(\mathrm{HC} \mathrm{p}<0.001$; CF $\mathrm{p}=0.028$; asthma $\mathrm{p}<0.001$; CSLD $\mathrm{p}=0.002)$. Using the NIOX $\mathrm{MINO}^{\circ}$ sampling at $2 \mathrm{ml} / \mathrm{sec}$, patients with PCD had significantly lower $\mathrm{nNO}$ measurements than $\mathrm{HC}(\mathrm{p}<0.001), \mathrm{CF}(\mathrm{p}=0.001)$ and asthma $(\mathrm{p}<0.001)$. However, two participants with CSLD had very low levels $(<6 \mathrm{~nL} / \mathrm{min})$ and there was no statistical difference in $\mathrm{nNO}$ values between this group and those with PCD $(\mathrm{p}=0.11)$. One participant with CF and normal ciliary function and ciliary ultrastructure, had very low levels of $\mathrm{nNO}(<30 \mathrm{~nL} / \mathrm{min})$ measured using the $\mathrm{NIOX}^{\circ}$ Flex and NIOX MINO ${ }^{\circ}$.

Receiver operating characteristic (ROC) curves were generated for the $\mathrm{NIOX}^{\circ}$ Flex and NIOX $\mathrm{MINO}^{\circ}$ at $2 \mathrm{ml} / \mathrm{sec}$ and $5 \mathrm{ml} / \mathrm{sec}$ in cases with $\mathrm{PCD}$ versus participants without PCD (curves not shown) and cut-off values were determined for optimal sensitivity and specificity (Table 1). Using NIOX ${ }^{\circ}$ Flex, a nNO cut off levels of $38 \mathrm{~nL} / \mathrm{min}$ had $100 \%$ sensitivity and $95 \%$ specificity for distinguishing PCD patients from non-PCD patients. A cut off value of $30 \mathrm{~nL} / \mathrm{min}$ when using the NIOX $\mathrm{MINO}^{\circ}$ sampling at $5 \mathrm{ml} / \mathrm{sec}$, provided $100 \%$ sensitivity and $95 \%$ specificity; using the same analyser, sampling at $2 \mathrm{ml} / \mathrm{sec}$, a cut of value of $43 \mathrm{~nL} / \mathrm{min}$ provided $100 \%$ sensitivity and $93 \%$ specificity for differentiating PCD patients from the other groups.

\section{Comparison of $\mathrm{nNO}$ values between analysers}

Comparing analysers, within patients, the NIOX MINO ${ }^{\circ}$ sampling at $5 \mathrm{ml} / \mathrm{sec}$ or $2 \mathrm{ml} / \mathrm{sec}$ consistently measured lower $(\mathrm{p}<0.001, \mathrm{p}<0.001)$ than the $\mathrm{NIOX}^{\oplus}$ Flex (Figures 1, 2, 3). Pearson correlation analysis showed excellent linear association between $\mathrm{nNO}$ readings obtained by $\mathrm{NIOX}^{\circ}$ Flex and NIOX MINO ${ }^{\circ}$ at $5 \mathrm{ml} / \mathrm{sec}$ or $2 \mathrm{ml} / \mathrm{sec}$ $(\mathrm{r}=0.93 \mathrm{p}<0.001$ and $\mathrm{r}=0.93 \mathrm{p}<0.001$ respectively). The relationship between the $\mathrm{nNO}$ measured by $\mathrm{NIOX}^{\circ}$ Flex and NIOX $\mathrm{MINO}^{\circ}$ at $5 \mathrm{ml} / \mathrm{sec}$ were further investigated by Bland-Altman plot (Figure 4). The Bland-Altman plots show a high degree of difference between readings from the two analysers, particularly in participants with very high levels of nNO. However the patients with PCD all had low nNO levels, and this group all demonstrated low variability of readings between analysers.

\section{Reproducibility within-analyser}

The intra-subject\%CV showed good repeatability between three measurements taken during the same visit using $\mathrm{NIOX}^{\circ}$ Flex $(\% \mathrm{CV}=9)$ and reasonable repeatability

\begin{tabular}{|c|c|c|c|}
\hline & $\begin{array}{l}\mathrm{NIOX}^{\oplus} \text { Flex } \\
\text { Breath-hold }\end{array}$ & $\begin{array}{l}\text { Niox } \text { Mino }_{5 \mathrm{ml} / \mathrm{sec}} \\
\text { Tidal breathing }\end{array}$ & $\begin{array}{c}{\text { Niox } \mathrm{Mino}_{2 \mathrm{ml} / \mathrm{sec}}}_{\text {Tidal breathing }}\end{array}$ \\
\hline $\begin{array}{l}\text { nNO cut-off value } \\
(\mathrm{nL} / \mathrm{min})\end{array}$ & 38 & 30 & 43 \\
\hline Sensitivity\% & 100 & 100 & 100 \\
\hline Specificity\% & 95 & 95 & 93 \\
\hline
\end{tabular}




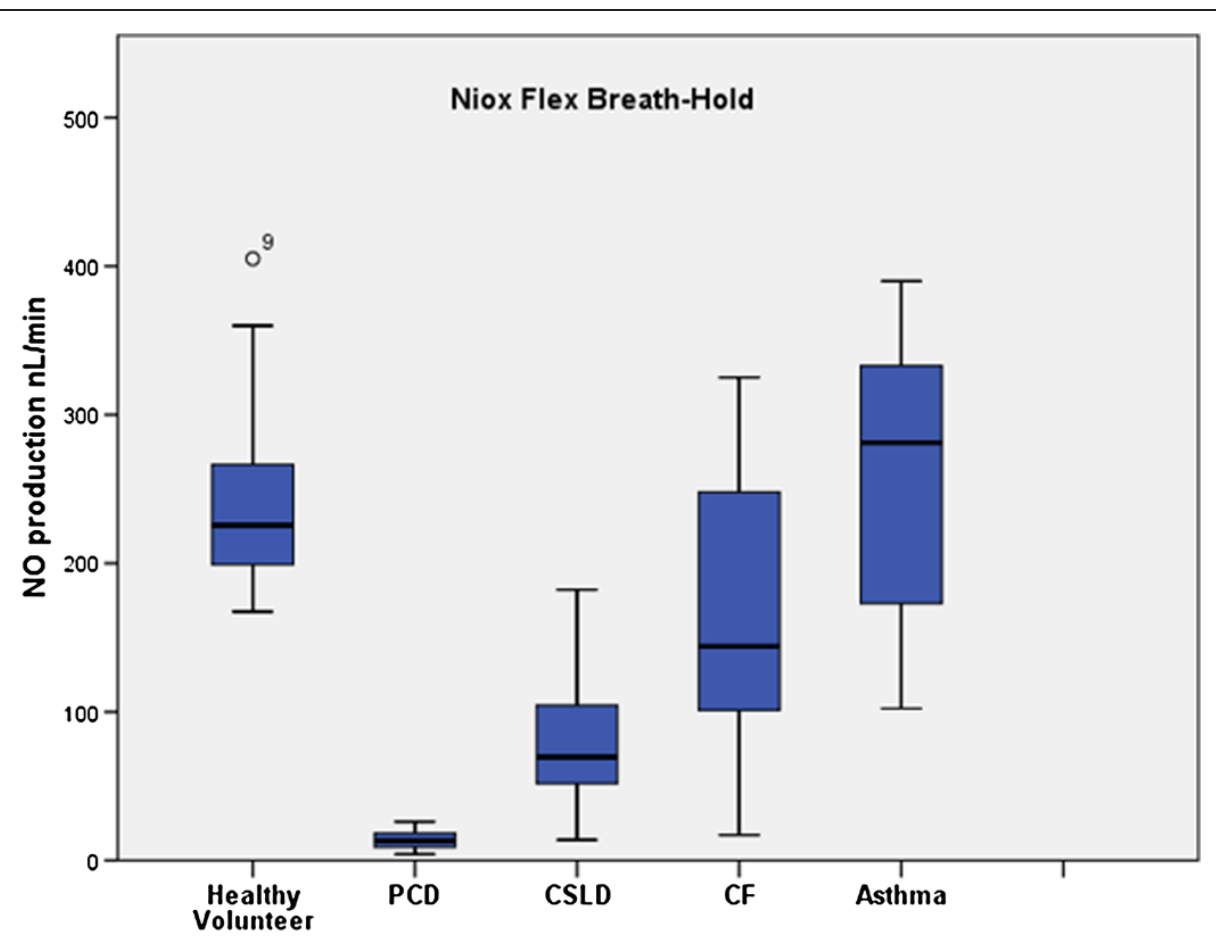

Figure 1 Box plots demonstrating nasal NO production ( $\mathrm{nL} / \mathrm{min}$ ) measured by NIOX ${ }^{\circledR}$ Flex using a breath-hold manoeuver in healthy volunteers $(n=15), \operatorname{PCD}(n=11), \operatorname{CSLD}(n=6), \operatorname{CF}(n=6)$ and asthma $(n=9)$ (line: median, box: quartiles, whiskers: minimum and maximum.

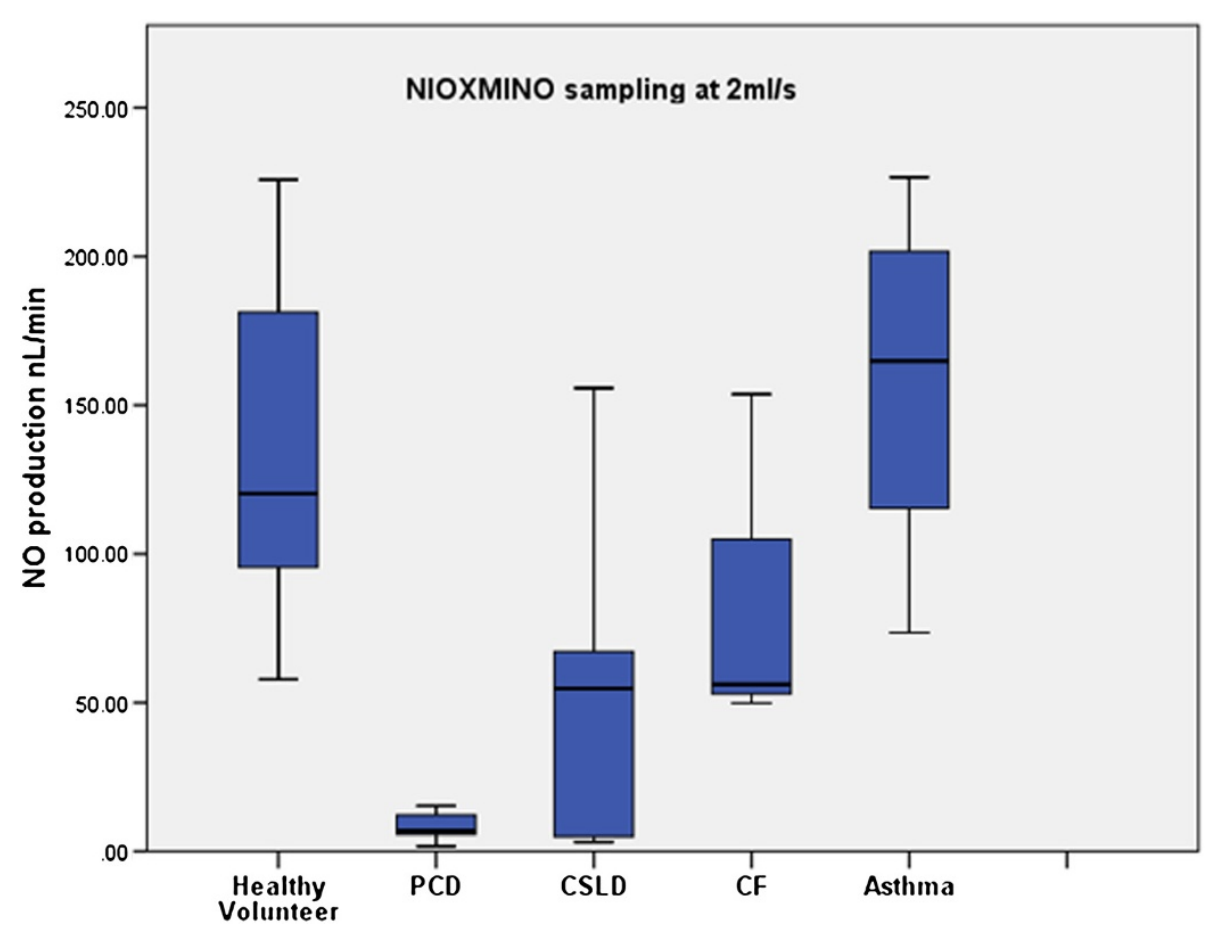

Figure 2 Box plots demonstrating nasal NO production $(\mathrm{nL} / \mathrm{min})$ measured by NIOX MINO ${ }^{\circledR}$ during mouth breathing with nasal sampling at $2 \mathrm{ml} / \mathrm{sec}$ in healthy volunteers $(n=13), \operatorname{PCD}(n=9), \operatorname{CSLD}(n=5), \operatorname{CF}(n=3)$ and asthma $(n=8)$. 


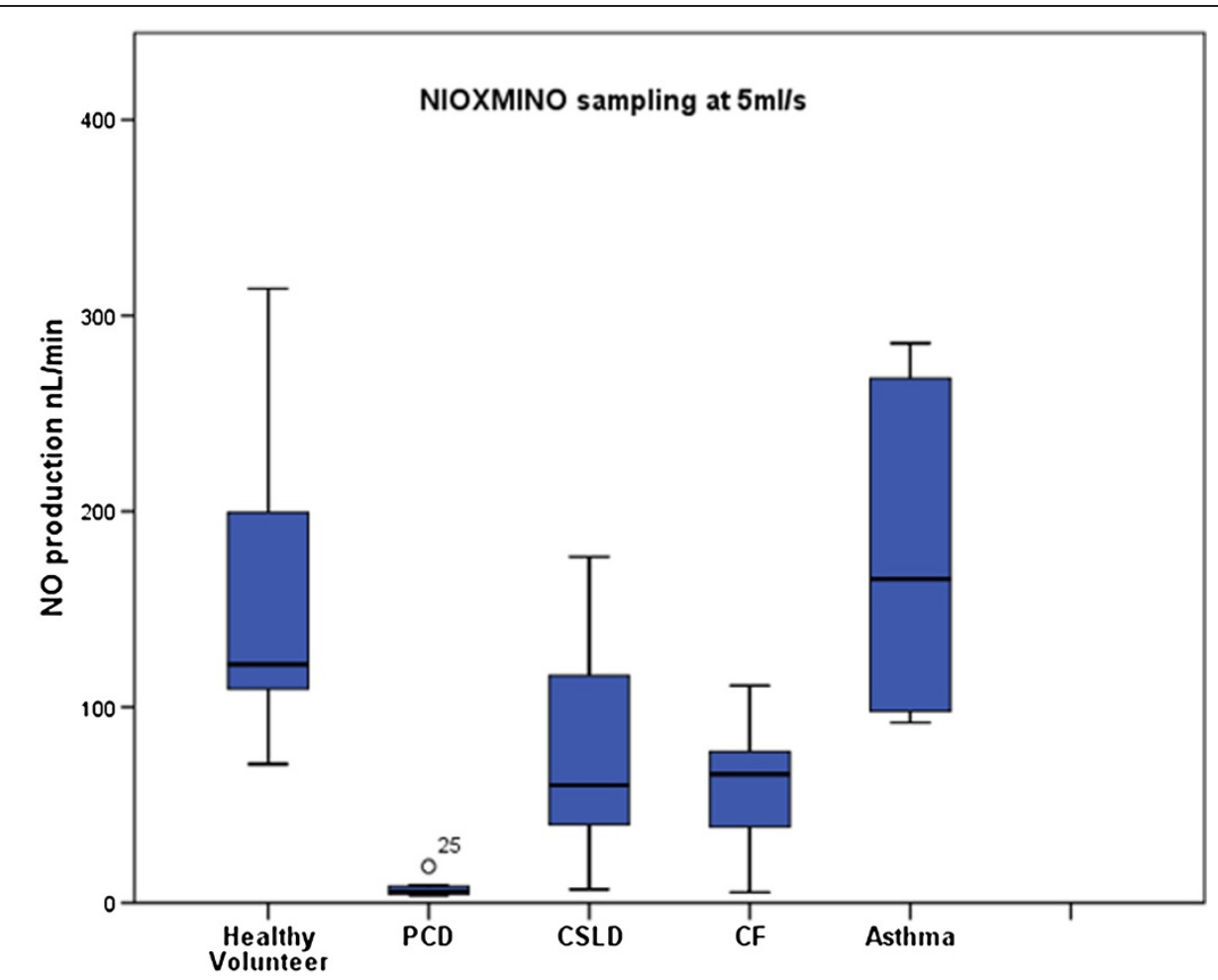

Figure 3 Box plots demonstrating nasal NO production $(\mathrm{nL} / \mathrm{min})$ measured by NIOX MINO ${ }^{\otimes}$ during mouth breathing with nasal sampling at $5 \mathrm{ml} / \mathrm{sec}$ in healthy volunteers $(n=15), \operatorname{PCD}(n=12), \operatorname{CSLD}(n=7), \operatorname{CF}(n=5)$ and asthma $(n=9)$.

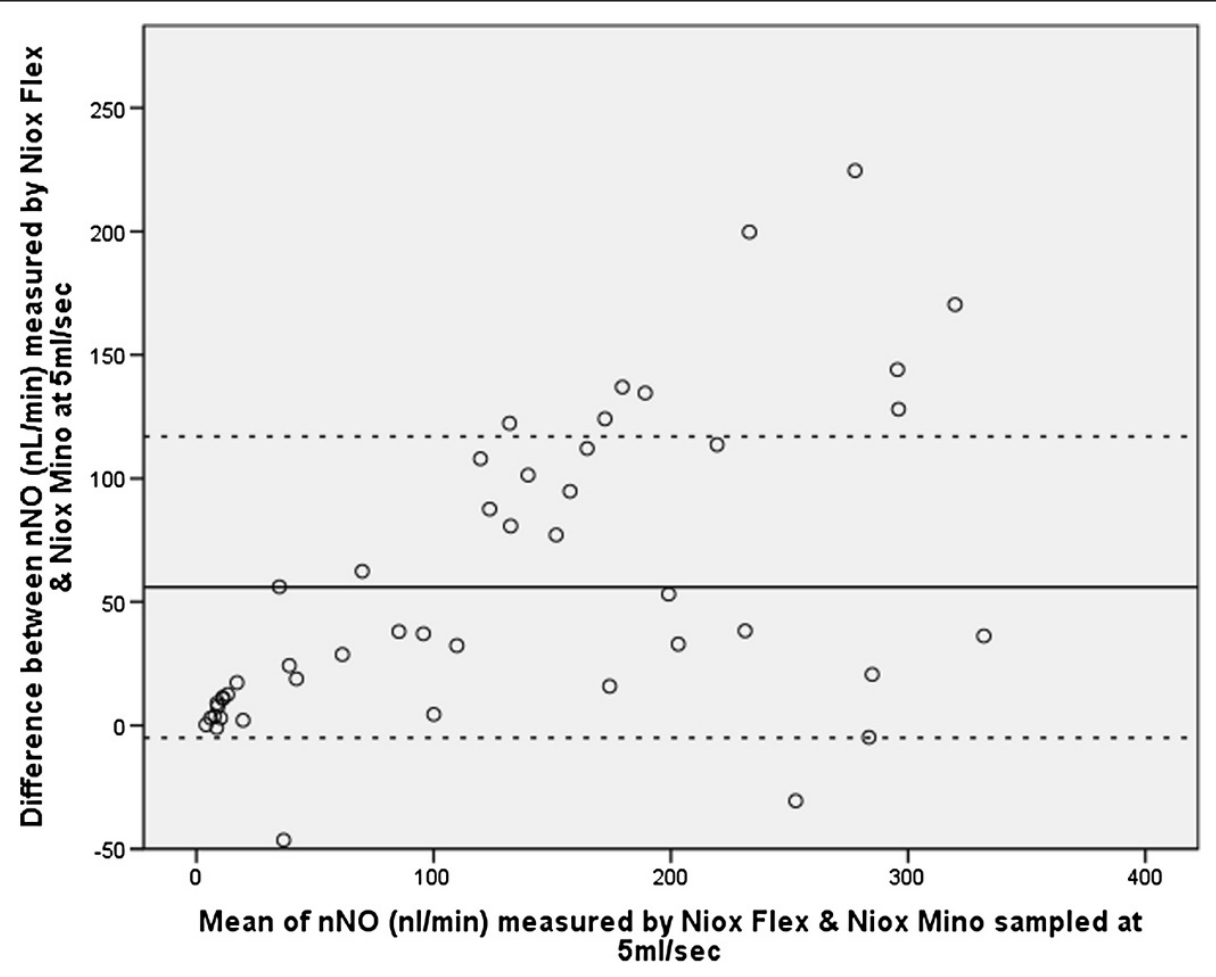

Figure 4 Bland Altman plots comparing the $\mathrm{NIOX}^{\circledR}$ Flex with $\mathrm{NIOX}^{\mathrm{MINO}}{ }^{\circledR}$ at $\mathbf{5} \mathrm{ml} / \mathrm{sec}$. Each point represents the difference between the $\mathrm{nNO}$ readings ( $\mathrm{nL} / \mathrm{min}$ ) obtained from a patient using the two analysers versus the mean of the two measurements. The reference lines represent the mean (and 1.96*SD) inter-analyser differences. 
using the NIOX $\mathrm{MINO}^{\circ}$ at $5 \mathrm{ml} / \mathrm{sec}(\% \mathrm{CV}=15)$ and $\mathrm{NIOX} \mathrm{MINO}^{\circ}$ at $2 \mathrm{ml} / \mathrm{sec}(\% \mathrm{CV}=14)$.

\section{Usability of the analysers}

Prior to the study the nurse specialist and physiotherapist were highly experienced obtaining nNO readings from adults and children using the $\mathrm{NIOX}^{\circ}$ Flex breathhold protocol. They were unable to obtain readings with the NIOX $\mathrm{MINO}^{\circ}$ using the breath-hold technique because even healthy adults were unable to breath-hold for the requisite time. Their assessment (Table 2) was that younger children were sometimes able to achieve $\mathrm{nNO}$ readings using the NIOX $\mathrm{MINO}^{\circ}$ by using the mouth breathing technique with sampling at $5 \mathrm{ml} / \mathrm{sec}$, even when acceptable reading were not obtained using the $\mathrm{NIOX}^{\circ}$ Flex. However, the NIOX $\mathrm{MINO}^{\circ}$ sampling at $2 \mathrm{ml} / \mathrm{sec}$ was a very lengthy procedure and fewer participants achieved it.

The portability of the NIOX $\mathrm{MINO}^{\circ}$ was considered a benefit by health care professionals involved in the study, although the need to be placed on a firm, flat surface and the short sampling tube were poorer ergonomic features.

\section{Discussion and conclusions}

This study confirmed that the hand-held NIOX MINO provides a reliable screening tool for PCD compared to the NIOX ${ }^{\circ}$ Flex in this study population. This is consistent with two previous studies using a hand held device in PCD patients, one of which collected nasal gas via a tight fitting nasal mask during single expiration silent breathing or humming [15]. The other study compared a tidal breathing and breath-hold maneuvers (+/- velum closure) [18]. We were unable to obtain readings using the NIOX $\mathrm{MINO}^{\circ}$ during breath-holding but found NIOX MINO ${ }^{\circ} \mathrm{nNO}$ readings taken during mouth breathing correlated well with measurements from the $\mathrm{NIOX}^{\circ}$ Flex during breath-holding manoeuvres. This was particularly true for patients with PCD. Within our study population, we were more successful ( $96 \%$ versus $76 \%$ success) and quicker (15-30 minutes versus 20 40 minutes) measuring $\mathrm{nNO}$ using the $\mathrm{NIOX}^{\mathrm{MINO}}{ }^{\circ}$ at $5 \mathrm{ml} / \mathrm{sec}$ than at $2 \mathrm{ml} / \mathrm{sec}$; we found no advantage for measuring at $2 \mathrm{ml} / \mathrm{sec}$ and would use $5 \mathrm{ml} / \mathrm{sec}$ in the future. A recent Danish study [18] using the NIOX MINO ${ }^{\circ}$ similarly reported that the method recommended by ATS/ERS guidelines for measuring $\mathrm{nNO}$ [20] (aspiration of nasal gas during velum closure and breath-hold) was impossible at a sampling rate of $2 \mathrm{ml} / \mathrm{sec}$, but they had a success rate of $70 \%$ during breath-hold at a rate of $5 \mathrm{ml} / \mathrm{sec}$. This compared to $100 \%$ success when sampling at $5 \mathrm{ml} / \mathrm{sec}$ during tidal breathing [18].

We noted that all three methods gave reproducible results. Although the methods were well correlated, there were differences in the mean $\mathrm{nNO}$ levels between analysers. $\mathrm{nNO}$ production recorded by the NIOX $\mathrm{MINO}^{\circ}$ was lower than that recorded by the NIOX ${ }^{\bullet}$ Flex. This is likely to reflect contamination of the nasal sample by lower

Table 2 Comparison of analysers and methods reflecting the opinions of the multidisciplinary specialist PCD team having conducted the research

\begin{tabular}{|c|c|c|}
\hline & NIOX ${ }^{\oplus}$ Flex 20 seconds & NIOX MINO ${ }^{\circledast}$ \\
\hline Ease of use & $\begin{array}{l}\text { Easily used by children over } 8 \text { years and by } \\
\text { some younger using breath hold (BH) }\end{array}$ & $\begin{array}{l}\text { Breath hold difficult for } 45 \mathrm{sec} / 90 \mathrm{sec} \text { by all ages. } \\
\text { Tidal breathing (TB) easily achieved in } 5 \mathrm{ml} / \mathrm{sec} \\
\text { sampling mode }\end{array}$ \\
\hline Time to complete 3 readings & 5-10 $\min (\mathrm{BH})$ & $20-40 \min (T B)$ \\
\hline \multirow[t]{3}{*}{ Practical issues } & $\begin{array}{l}\text { Needs stable environment and dedicated } \\
\text { work space. }\end{array}$ & Needs to be used on a flat surface \\
\hline & Poor portability & Excellent portability \\
\hline & $\begin{array}{l}\text { Breath-holding technique difficult for young } \\
\text { children and advanced lung disease }\end{array}$ & $\begin{array}{l}\text { Most people could manage the technique but it } \\
\text { resulted in a dry mouth. Short sampling catheter }\end{array}$ \\
\hline Cost of machine & Very Expensive. Approx $£ 30,000$ & Expensive. Approx $£ 2,100$ \\
\hline Need for calibration gases & Yes. Approx $£ 1,500$ per annum & No- autocalibrates \\
\hline Need for maintenance service & Yes. Approx $£ 3,800$ per annum & No \\
\hline Consumables & Nasal sampling olives: $£ 40$ per 100 & Nasal sampling olives: $£ 40$ per 100 patients \\
\hline Longevity & Good & $\begin{array}{l}\text { Sensor needs replacing after } 100 \text { or } 300 \text { readings } \\
\text { (using our protocol } 30 \text { or } 100 \text { patients). Many } \\
\text { readings failed but were still 'counted'. Sensor } \\
\text { expires after } 1 \text { year Approx. } £ 1,215 \text { for sensor } 300 \text {. }\end{array}$ \\
\hline Range of $\mathrm{nNO}(\mathrm{ppb})$ & $25-2000 \mathrm{ppb}$ & 5-1700 ppb \\
\hline $\begin{array}{l}\text { Effected by other electronic devices } \\
\text { in room e.g. mobile phones }\end{array}$ & No & Yes \\
\hline
\end{tabular}


airway gas during mouth breathing and short mucosal contact time. This demonstrates the need for different diagnostic cut-offs for different breathing methods. Using a stationary chemiluminescence $\mathrm{NO}$ analyser, a study [21] of 85 children including 20 with PCD similarly demonstrated that non-velum closure methods yielded lower values that during the velum closure technique recommended in ATS/ ERS guidelines [20]. As confirmed by our study, the authors reported open mouth tidal breathing provides reproducible and discriminatory $\mathrm{nNO}$ levels. Since measurement during tidal breathing is easier to perform, allowing its use in young children, standardisation of this approach and reference data is called for.

In our population, a cut-off value of $38 \mathrm{~nL} / \mathrm{min}$ provided $100 \%$ sensitivity and $95 \%$ specificity using the $\mathrm{NIOX}^{\odot}$ Flex during breath-hold. A cut-off of $30 \mathrm{~nL} / \mathrm{min}$ using the NIOX $\mathrm{MINO}^{\circ}$ (tidal breathing with sampling at $5 \mathrm{ml} / \mathrm{sec}$ ) provided $100 \%$ sensitivity and $95 \%$ specificity. These cut off values are somewhat lower that those reported in a large study investigating the use of $\mathrm{nNO}$ as a screening test for PCD [9]. Leigh et al. determined a cut off value of $77 \mathrm{~nL} / \mathrm{min}$ was $98 \%$ sensitive and $>99.9 \%$ specific when screening patients at their PCD centre. The authors then used the same protocol to measure nNO in 155 patients referred for PCD diagnostic testing at six other hospitals. They found that this level correctly identified 70 of the 71 participants who were confirmed to have PCD. A study using the $\mathrm{NIOX}^{\circledR}$ Flex and $\mathrm{NIOX} \mathrm{MINO}^{\circ}$ to measure nNO during silent and humming exhalations [2,17] calculated lower cut-off values than in our study. This is likely to reflect greater contamination by lower airway gases during these exhalation manoeuvres. Importantly, the key findings of both manuscripts were in line with our paper, i.e. PCD patients have lower $\mathrm{nNO}$ than healthy controls or CF patients $[9,17]$, and the hand-held device is effective for screening to differentiate PCD from other groups [17].

Whilst there is now substantial data to demonstrate that $\mathrm{nNO}$ measurement is helpful in guiding the diagnostic pathway, we need to recognize limitations of this measurement [10]. Standardized methods to measure $\mathrm{nNO}$ are not appropriate for younger children, precisely the age group that need targeting for diagnostic measurement. Sampling during tidal breathing provides a potential method in this group, but data is limited [22]. Low nNO has previously been described in patients with CF and other respiratory conditions. One of our patients with CF and negative PCD diagnostics had very low levels of $\mathrm{nNO}\left(\mathrm{NIOX}^{\curvearrowleft}\right.$ Flex $17 \mathrm{~nL} / \mathrm{min}, \mathrm{NIOX} \mathrm{MINO}^{\circ} 5 \mathrm{ml} / \mathrm{Sec}$ $5 \mathrm{~nL} / \mathrm{min}$ ). Two patients with CSLD also had low levels of nNO. Both had PCD excluded using protocols that follow ERS guidelines [2]. They had normal ciliary beat frequency and pattern before and following culture at air liquid interface. They also had normal ultrastructure by
TEM. These data demonstrate that although nNO is useful as a screening test, it is not a substitute for formal assessment of ciliary function and assessment of ciliary ultrastructure. It is noteworthy that although all PCD patients in this study had very low levels of $\mathrm{nNO}$, occasionally PCD patients with normal levels have been described $[8,22,23]$. This highlight that patients with a history strongly suggestive of PCD should not be excluded from further diagnostic evaluation on the basis of $\mathrm{nNO}$.

An important observation by the authors has arisen from referrals to our diagnostic service where $\mathrm{nNO}$ has been measured by the referring team using NIOX MINO ${ }^{\circ}$. A number of patients have been noted to have extremely low levels of nNO at the referring hospital, but normal/ high levels when measured using the NIOX $\mathrm{MINO}^{\circ}$ or $\mathrm{NIOX}^{\oplus}$ Flex at our centre. We suspect this might reflect leaks at the nares or excessive lower airway contamination, and highlights the need for training and standardised protocols if the NIOX $\mathrm{MINO}^{\circ}$ is to be used as a screening test at satellite hospitals.

In summary, nNO measurements using the NIOX $\mathrm{MINO}^{\circ}$ successfully discriminates $\mathrm{PCD}$ patients from healthy individuals and those with other lung conditions. Nasal NO values were reproducible and correlated well with the $\mathrm{NIOX}^{\oplus}$ Flex. However, we consistently recorded lower readings using the tidal breathing maneuver. The NIOX $\mathrm{MINO}^{\circ}$ is easily portable and relatively costeffective as compared to the desktop NIOX ${ }^{\circledR}$ Flex. Health care professionals and patients found it acceptable. Handheld devices therefore provide a promising screening tool for PCD although further studies will be required to establish reference data for each breathing maneuver and analyser. One study has successfully attempted to standardise methodology across a number of collaborating sites with different analysers [9]. With the array of sampling techniques and analysers available, standardised protocols and cut off data should be developed. Due to the rarity of PCD it is likely that a coordinated international approach will be required to achieve this.

\section{Competing interests}

The authors declare that they have no competing interests.

\section{Authors' contributions}

$\mathrm{AH}$ had the idea for the research and designed the study; EB, KG, RJ \& JP undertook clinical testing and data recording; $\mathrm{AH}, \mathrm{HE}$ and JSL undertook data analysis and interpretation; HE, WW \& JSL recruited patients and are clinical leads for the PCD diagnostic service; all authors contributed to and approved the manuscript; JSL takes responsibility for the integrity of the study data and analysis. All authors read and approved the final manuscript.

\section{Acknowledgements}

The Primary Ciliary Dyskinesia Centre Southampton is funded by the National Specialised Commissioning Team, NHS England. This study was supported by the Southampton NIHR Wellcome Trust Clinical Research Facility and NIHR Southampton Respiratory Biomedical Research Unit. Aerocrine loaned the $\mathrm{NIOX} \mathrm{MINO}^{\oplus}$ to evaluate its use in our clinic population. 


\section{Author details}

${ }^{1}$ Primary Ciliary Dyskinesia Centre, University Hospital Southampton NHS Foundation Trust, Southampton, UK. ${ }^{2}$ NIHR Southampton Respiratory Biomedical Research Unit, University of Southampton and University Hospital Southampton NHS Foundation Trust, Southampton, UK. ${ }^{3}$ Clinical and Experimental Sciences Academic Unit (Mail Point 803), University of Southampton Faculty of Medicine, University Hospital Southampton NHS Foundation Trust, Tremona Road, Southampton SO16 6YD, UK.

\section{Received: 9 January 2013 Accepted: 4 February 2014}

Published: 10 February 2014

\section{References}

1. Lucas JS, Walker WT, Kuehni CE, Lazor R: Primary ciliary dyskinesia. In Orphan Lung Diseases. Edited by Courdier J-F. UK: European Respiratory Monograph; European Respiratory Society Publications; 2011:201-217.

2. Barbato A, Frischer T, Kuehni CE, Snijders D, Azevedo I, Baktai G, Bartoloni L, Eber E, Escribano A, Haarman E, Hesselmar B, Hogg C, Jorissen M, Lucas J, Nielsen KG, O'Callaghan C, Omran H, Pohunek P, Strippoli MP, Bush A: Primary ciliary dyskinesia: a consensus statement on diagnostic and treatment approaches in children. Eur Respir J 2009, 34:1264-1276.

3. Bush A, Chodhari R, Collins N, Copeland F, Hall P, Harcourt J, Hariri M, Hogg C, Lucas J, Mitchison HM, O'Callaghan C, Phillips G: Primary ciliary dyskinesia: current state of the art. Arch Dis Child 2007, 92:1136-1140.

4. O'Callaghan C, Chilvers M, Hogg C, Bush A, Lucas J: Diagnosing primary ciliary dyskinesia. Thorax 2007, 62:656-657.

5. Kuehni CE, Frischer T, Strippoli MP, Maurer E, Bush A, Nielsen KG, Escribano A, Lucas JS, Yiallouros P, Omran H, Eber E, O'Callaghan C, Snijders D, Barbato A: Factors influencing age at diagnosis of primary ciliary dyskinesia in European children. Eur Respir J 2010, 36:1248-1258.

6. Karadag B, James AJ, Gultekin E, Wilson NM, Bush A: Nasal and lower airway level of nitric oxide in children with primary ciliary dyskinesia. Eur Respir J 1999, 13:1402-1405.

7. Wodehouse T, Kharitonov SA, Mackay IS, Barnes PJ, Wilson R, Cole PJ: Nasal nitric oxide measurements for the screening of primary ciliary dyskinesia. Eur Respir J 2003, 21:43-47.

8. Walker WT, Jackson CL, Lackie PM, Hogg C, Lucas JS: Nitric oxide in primary ciliary dyskinesia. Eur Respir J 2012, 40:1024-1032.

9. Leigh MW, Hazucha MJ, Chawla KK, Baker BR, Shapiro AJ, Brown DE, Lavange LM, Horton BJ, Qaqish B, Carson JL, Davis SD, Dell SD, Ferkol TW, Atkinson JJ, Olivier KN, Sagel SD, Rosenfeld M, Milla C, Lee HS, Krischer J, Zariwala MA, Knowles MR: Standardizing nasal nitric oxide measurement as a test for primary ciliary dyskinesia. Ann Am Thorac Soc 2013, 10(6):574-581.

10. Lucas JS, Walker WT: Nitric oxide is an important test in the diagnostic pathway for primary ciliary. Ann Am Thorac Soc 2013. in press.

11. Boot JD, de Ridder L, de Kam ML, Calderon C, Mascelli MA, Diamant Z: Comparison of exhaled nitric oxide measurements between NIOX MINO electrochemical and Ecomedics chemiluminescence analyzer. Respir Med 2008, 102:1667-1667.

12. Kim SH, Moon JY, Kwak HJ, Kim SI, Park DW, Kim JW, Kim TH, Sohn JW, Shin DH, Park SS, Yoon HJ: Comparison of two exhaled nitric oxide analyzers: the NIOX MINO hand-held electrochemical analyzer and the NOA280i stationary chemiluminescence analyzer. Respirology 2012, 17:830-834.

13. Schiller B, Hammer J, Barben J, Trachsel D: Comparability of a hand-held nitric oxide analyser with online and offline chemiluminescence-based nitric oxide measurement. Pediatr Allergy Immunol 2009, 20:679-685.

14. Selby A, Clayton B, Grundy J, Pike K, Drew K, Raza A, Kurukulaaratchy R, Arshad SH, Roberts G: Are exhaled nitric oxide measurements using the portable NIOX MINO repeatable? Respir Res 2010, 11:43.

15. Maniscalco M, de Laurentiis G, Weitzberg E, Lundberg JO, Sofia M: Validation study of nasal nitric oxide measurements using a hand-held electrochemical analyser. Eur J Clin Invest 2008, 38:197-200.

16. Weschta $M$, Deutschle $T$, Riechelmann $H$ : Nasal fractional exhaled nitric oxide analysis with a novel hand-held device. Rhinology 2008, 46:23-27.

17. Montella S, Alving K, Maniscalco M, Sofia M, De SS, Raia V, Santamaria F: Measurement of nasal nitric oxide by hand-held and stationary devices. Eur J Clin Invest 2011, 41:1063-1070.

18. Marthin JK, Nielsen KG: Hand-held tidal breathing nasal nitric oxide measurement-a promising targeted case-finding tool for the diagnosis of primary ciliary dyskinesia. PLoS One 2013, 8:e57262.
19. Bush A, Cole P, Hariri M, Mackay I, Phillips G, O'Callaghan C, Wilson R, Warner JO: Primary ciliary dyskinesia: diagnosis and standards of care. Eur Respir J 1998, 12:982-988.

20. American Thoracic Society; European Respiratory Society: ATS/ERS recommendations for standardized procedures for the online and offline measurement of exhaled lower respiratory nitric oxide and nasal nitric oxide,2005. Am J Respir Crit Care Med 2005, 171(8):912-30.

21. Mateos-Corral D, Coombs R, Grasemann H, Ratjen F, Dell SD: Diagnostic value of nasal nitric oxide measured with non-velum closure techniques for children with primary ciliary dyskinesia. J Pediatr 2011, 159:420-424.

22. Marthin JK, Nielsen KG: Choice of nasal nitric oxide technique as first-line test for primary ciliary dyskinesia. Eur Respir J 2011, 37:559-565.

23. Pifferi M, Bush A, Caramella D, Di CM, Zangani M, Chinellato I, Macchia P, Boner AL: Agenesis of paranasal sinuses and nasal nitric oxide in primary ciliary dyskinesia. Eur Respir J 2011, 37:566-571.

doi:10.1186/1471-2466-14-18

Cite this article as: Harris et al:: Validation of a portable nitric oxide analyzer for screening in primary ciliary dyskinesias. BMC Pulmonary Medicine 2014 14:18.

\section{Submit your next manuscript to BioMed Central and take full advantage of:}

- Convenient online submission

- Thorough peer review

- No space constraints or color figure charges

- Immediate publication on acceptance

- Inclusion in PubMed, CAS, Scopus and Google Scholar

- Research which is freely available for redistribution

Submit your manuscript at www.biomedcentral.com/submit
C BioMed Central 